\title{
CLOSURE OF SUBCUTANEOUS FAT IN OBESE PATIENTS: A PROSPECTIVE RANDOMISED STUDY IN ABDOMINAL INCISIONS
}

\author{
Himanshu Chandel ${ }^{1}$, Mukesh Singh Narwaria ${ }^{2}$, Amit Ojha ${ }^{3}$
}

${ }^{1}$ Assistant Professor, Department of Surgery, G. R. Medical College, Gwalior, Madhya Pradesh.

${ }^{2}$ Assistant Professor, Department of Surgery, G. R. Medical College, Gwalior, Madhya Pradesh.

${ }^{3}$ Assistant Professor, Department of Surgery, G. R. Medical College, Gwalior, Madhya Pradesh.

\section{ABSTRACT}

\section{BACKGROUND}

Obesity is a complex medical disorder characterised by an excess of total body fat. Traditionally, abdominal wall closure is performed using a three layer technique in which the parietal peritoneum with posterior rectus sheath, anterior rectus sheath and skin are individually and sequentially closed. Camper's fascia provides a potential space for haematoma and seroma formation. The vascular supply to subcutaneous fat is relatively poor making this tissue susceptible to infection.

\section{MATERIALS AND METHODS}

The study was a prospective randomised study done in the Department of Surgery in our Institution for a period of two years. In this study, a total number of 59 patients were included. All the patients were obese according to the body mass index criteria (BMI > 30 for male and BMI > 28.6 for female). Patients were assigned randomly into three groups before they underwent any surgery. In Group A subcutaneous fat was approximated, in Group B subcutaneous fat was not approximated and in Group C only subcutaneous Romovac suction drain was used.

\section{RESULTS}

A total of 21 patients were included in Group A, 20 patients in Group B and 18 patients were included in Group C. Matching was done for age subcutaneous fat thickness and BMI, when any two groups were compared. The three groups were comparable with respect to age, subcutaneous fat thickness and BMI. The wound complication rate was $0 \%$ in closure group versus $15 \%$ in non-closure group. The wound infection rate was $0 \%$ in closure group versus $5 \%$ in non-closure group. The difference in the soilage of dressings (40.8 $\mathrm{cm}^{2}$ closure group versus $60.95 \mathrm{~cm}^{2}$ non-closure group) was significant $(\mathrm{p}<0.001)$ between the two groups.

\section{CONCLUSION}

The difference of soilage ( $60.95 \mathrm{~cm}^{2}$ non-closure group versus $29.05 \mathrm{~cm}^{2}$ drainage group) of dressings between subcutaneous suction drain closure and non-closure was also significant, $\mathrm{p}<0.001$. Between subcutaneous fat closure and subcutaneous suction drain closure, there is no decided advantage of one over the other in terms of morbidity.

\section{KEYWORDS}

Subcutaneous Fat, Laparotomy Wound, Abdominal Wound Closure.

HOW TO CITE THIS ARTICLE: Chandel H, Narwaria MS, Ojha A. Closure of subcutaneous fat in obese patients: a prospective randomised study in abdominal incisions. J. Evolution Med. Dent. Sci. 2016;5(85):6323-6326, DOI: 10.14260/jemds/2016/1428

\section{BACKGROUND}

Surgeons have had a great fear of blood in wounds since preantiseptic times. It was believed that the most feared and dangerous wound arose from its decomposition. Throughout that era, surgeons used various techniques in an effort to free the wound of blood. Insertion of drainage tubes into wounds to allow egress of blood was common practice for securing primary healing. A technique whereby wound healing was encountered without drainage of tubes was pioneered by Kocher. His method involved secondary suturing of the surgical wounds after the initial operations (Holl et al,1 1974). In 1984, Neuber and Kuster recommended complete obliteration of dead space by buried sutures as a means of minimising the accumulation of blood in the wound. Obesity

Financial or Other, Competing Interest: None.

Submission 30-07-2016, Peer Review 28-08-2016,

Acceptance 03-09-2016, Published 22-10-2016.

Corresponding Author:

Himanshu Chandel,

Koteshwar Colony, In Front of Koteshwar,

Mandir, Gwalior - 474003, Madhya Pradesh.

E-mail: drhimanshuchandel@gmail.com

DOI: $10.14260 /$ jemds/2016/1428 can impede the successful accomplishment of any surgical procedure. Injury to innocent organs and excessive blood loss are hazards inherent in surgery on the overweight patient. Further, abdominal operations in obese patients may lead to excessive blood loss, a technically compromised procedure and relatively prolonged operative time. Besides this there is a high risk in the post-operative period of thromboembolism, pulmonary and wound complications (Cruise et al,2 1980).

The obese is a unique subset of surgical patients. Wound complications (haematoma, seroma, infection, incisional hernia) cause significant morbidity in this group. Techniques and materials used in the closure of abdominal wounds in the obese must be continually reviewed in order to minimise the frequency of these problems.

The purpose of the study was to determine the role of subcutaneous fat approximation and to evaluate the role of suction drain in wound closure in obese patients.

Soper et $\mathrm{al}^{3}$ (1995) in their study confirmed that the thickness of the subcutaneous tissue was a significant risk factor for wound infection. In their study, no patient with a maximum depth of subcutaneous tissue $<3 \mathrm{~cm}$ had wound infection. In our study wound infection developed in one case, where subcutaneous fat thickness was $3.64 \mathrm{~cm}$. Besides this, 
the two patients in whom the wound complications occurred during the study also had their subcutaneous fat thickness $>3$ $\mathrm{cm}$. No patient in the study with subcutaneous fat thickness $<$ $3 \mathrm{~cm}$ developed wound complications. These results were comparable to the study of Soper et al. ${ }^{3}$

Various studies have assessed the effect of closure of dead space, in particular the development of seromas in patients undergoing mastectomy (Coveny et $\mathrm{al}^{4}$ 1993, Dwyer et $\mathrm{al}, 5$ 1991).

The importance of obliteration of dead space as a determinant of infection was examined by Condie and Ferguson $^{6}$ (1964) in an experimental study, in which they concluded that obliteration of potential dead space by suture reduces infection.

Naumann et $\mathrm{al}^{7}$ (1995) found that closure of the subcutaneous fat decreases the incidence of wound infection in obese patients.

Besides the use of subcutaneous stay sutures in obese patients (Sherman et al, ${ }^{8}$ 1984), the selective use of subcutaneous drains has also been reported to be associated with a low infection rate in a bariatric surgical series (Buck Walter et al, ${ }^{9}$ 1983).

Del Valle et al ${ }^{10}$ (1992) found a significantly higher incidence of wound disruption in patients who did not have their Camper's fascia approximated with suture. They found a significant increase in the incidence of wound disruption with a higher BMI. In this study, there was no incidence of wound disruption. But the three cases which had wound complications had BMI more than the mean BMI of that group.

Hussain et $\mathrm{al}^{11}$ (1990) found that there was no statistical difference in complications between closure and non-closure group. The dressings were significantly soiled by serosanguineous discharge in non-closure group as compared to closure group $\left(\mathrm{P}<0.04, \mathrm{X}^{2}\right.$ test). Our results were on the same line with no significant difference in the complication rate between the two groups (using standard error of proportion). There was significant difference in soilage $(\mathrm{P}<$ 0.001 ) of dressings between the two groups. Hence, the need for frequent dressings was observed in non-closure group.

Controversy remains over the use of drains in the subcutaneous space. Advocates argue that prophylactic drainage may eliminate "dead space" and reduce fluid accumulation known to be an excellent media for the growth of bacteria, therefore decreasing the postoperative infection rate. The selective use of subcutaneous drains has been reported to be associated with a low infection rate in bariatric surgical series.

Maitland et al12 (1970) conducted a study to find out the value of suction drainage in general surgery covering a period of 5 years under measure of control. The number of drained wounds observed was 1193, of this 858 were dealt with traditional methods and 335 by suction drainage. The results obtained showed that the latter method produces great improvement in the healing of operations on the genitourinary tract. Operations on breast, thyroid and herniotomies also benefitted to some extent.

In a report by Gallup et al $^{13}$ (1996), the complication rate was $25 \%$ with $20 \%(22 / 109)$ among the group receiving drain versus $31 \%(27 / 88)$ without a drain $(\mathrm{p}=0.09)$, in obese patients. In their study, 17 patients $(8.6 \%)$ had wound break down: 7 of 109 (6.4\%) with drains and 10 of 88 (11.4\%) without drains, $p=0.2$. These results though not statistically significant vary with what we found in this study. Wound complication rate was $0 \%(0 / 18)$ among the group receiving drain versus $15 \%$ (3/20) without a drain, standard error of proportion being significant. The infection rate $5 \%(1 / 20)$ in the group not receiving drain vs $0 \%(0 / 18)$ with drain was insignificant, SEP $<95 \%$ confidence limits. The difference can be attributed to the size of sample. Besides in the series of Gallup et al some of the patients received perioperative antibiotics and some did not, while in our study perioperative antibiotics were given to all.

No statistical superiority of closure of subcutaneous space over subcutaneous drain was found in this study. These findings are similar to those of Kozol et al. ${ }^{14}$ Still the soilage was significantly more $(\mathrm{p}<.001)$ in closure group vs drainage group. This factor had not been studied by Kozol et al.14

The superficial fascia in abdomen may be divided into a superficial fatty layer and a deep membranous layer. The fatty layer also known as fascia of Camper is continuous with the superficial fat over the rest of the body and may be extremely thick ( 3 inches or more in obese patients). The membranous layer also called as Scarpa's fascia fades out over the thoracic wall above and along the mid-axillary line laterally. Inferiorly, it passes onto the front of thigh where it fuses with the deep fascia, one finger breadth below the inguinal ligament. Scarpa's fascia is continued in the perineum as Colles' fascia. Traditionally, abdominal wall closure is performed using a three layer technique in which the parietal peritoneum with posterior rectus sheath, anterior rectus sheath and skin are individually and sequentially closed. Camper's fascia provides a potential space for haematoma and seroma formation. The vascular supply to subcutaneous fat is relatively poor making this tissue susceptible to infection. Haematoma, seroma, simple separation of the skin margins secondary to poor healing cause wound infection and subsequent disruption of the wound.

\section{MATERIALS AND METHODS}

This was a prospective randomised study conducted in the Department of Surgery, G. R. Medical College and associated with J. A. Group of Hospitals from September 2007 to October 2009. A total number of 59 patients were entered into the study. Each underwent elective abdominal surgery, which was performed by a fixed team of surgeons.

\section{Inclusion Criteria}

BMI (Body Mass Index) > 30 for male and BMI > 28.6 for females undergoing elective abdominal surgery, ASA Grade I/II, Preoperative stay in hospital $<3$ days.

\section{Exclusion Criteria}

Anaemia (Haemoglobin < 10 gm\%), Age > 65 years, Deranged kidney function test, Deranged liver function test, Diabetes mellitus, Duration of surgery $>3 \mathrm{hr}$., Immunocompromised, Koch's abdomen, Malignancy/taking cytotoxic drugs, Patients operated in emergency for acute abdomen. The patients were randomised into three groups.

\section{Group A}

Abdominal incisions with subcutaneous fat approximation.

\section{Group B}

Abdominal incisions without subcutaneous fat approximation. 


\section{Group C}

Abdominal incisions without subcutaneous fat approximation with suction drain.

Matching was done for (1) Age, (2) Sex, (3) Class of wound, (4) Thickness of subcutaneous fat and (5) BMI. Thickness of subcutaneous fat was measured in each case after incision. In Group A subcutaneous fat was approximated with absorbable suture (plain catgut 1-0) placed at a distance of $1 \mathrm{~cm}$. In Group $\mathrm{B}$, no attempt was made to approximate subcutaneous fat. In Group $\mathrm{C}$ besides not approximating subcutaneous fat suction drain was put, overlying anterior rectus/external oblique muscle. Drains were brought out through a separate stab wound. Skin was closed in all the groups with non-absorbable suture followed by aseptic dressing.

\section{POSTOPERATIVE FOLLOWUP AND LOCAL SITE WAS INSPECTED DAILY TO ASSESS \\ Wound Infection}

Surgical site was considered to be infected if within postoperative period of 3 days one of the following was present.

1. Purulent discharge.

2. Organism isolated from an aseptically obtained culture of fluid from site of incision.

3. Presence of redness, pain or tenderness, local swelling or if incision was deliberately opened by Surgeon.

4. Diagnosis of wound infection by Surgeon or attending physician.

\section{Soiling of Dressing}

Wound dressings were left undisturbed unless there was discharge or increase in discomfort/pain at wound site. Area of soilage was measured in square centimetres by transparent graph sheet being superimposed on the dressing.

\section{Haematoma/Seroma}

Any collection was drained under aseptic condition and sent for culture sensitivity. Depending upon the report, patient was managed accordingly by antibiotics and daily dressing. Suction drain were removed by 48-60 hrs. depending upon the amount of discharge. Tip of suction drain catheters were sent for culture and sensitivity. Postoperative followup was done weekly for 5 weeks after discharge.

\section{Factors Analysed and Compared}

Wound infection, seroma/haematoma formation, soiling of dressing, wound dehiscence, time consumed for subcutaneous fat closure.

\section{RESULTS AND ANALYSIS}

After matching different Groups A, B and C according to mean age, mean BMI, types of procedure and subcutaneous fat thickness following parameters were assessed.

\section{Wound Complications}

The wound infection rate in Group B was 5\% and the overall wound infection rate was $1.6 \%$. The wound complication rate in Group B was 15\% and overall wound complication rate was $5.08 \%$. 'Standard error of proportion' test was used to find the difference of complications and infection rate between the groups. 'Z' value > 95\% confidence limit was considered significant.

\begin{tabular}{|c|c|c|}
\hline & Complications & Infection \\
\hline Group A Vs Group B & Insignificant & Insignificant \\
\hline Group B Vs Group C & Significant & Insignificant \\
\hline Group C Vs Group A & Insignificant & Insignificant \\
\hline
\end{tabular}

\section{Wound Soakage $\left(\mathrm{cm}^{2}\right)$}

Statistically, significant difference was noted in wound soakage in the three groups. The wound soakage in Group A was $40.80+5.31 \mathrm{~cm}^{2}$, in Group B was $60.95+4.7 \mathrm{~cm}^{2}$ and in Group C was $29.05+3.6 \mathrm{~cm}^{2}$.

\section{CONCLUSION}

\section{Subcutaneous Fat Closure Vs Non-Closure}

The wound complication rate was $0 \%$ in closure group Vs $15 \%$ in non-closure group. The wound infection rate was $0 \%$ in closure group versus $5 \%$ in non-closure group. The difference was insignificant using standard error of proportion $<95 \%$ confidence limits. The difference in the soilage of dressings ( $40.8 \mathrm{~cm}^{2}$ closure group versus $60.95 \mathrm{~cm}^{2}$ non-closure group) was significant $(\mathrm{p}<0.001)$ between the two groups. The time required for subcutaneous fat closure was 3 mins 5 secs +51 secs, which did not unduly prolong any surgery. It is concluded that suturing subcutaneous fat in the obese reduces wound seepage and may cut the requirement for post-operative dressings.

\section{Subcutaneous Suction Drain Vs Non-Closure}

Using standard error of proportion, the wound complication rate of difference between the two groups was found to be significant $>95 \%$ confidence interval. The three wound complications in the non-closure group occurred in patients with subcutaneous fat thickness $>3.6 \mathrm{~cm}$. The difference of soilage $\left(60.95 \mathrm{~cm}^{2}\right.$ non-closure group versus $29.05 \mathrm{~cm}^{2}$ drainage group) of dressings between the two groups was also significant $\mathrm{p}<0.001$. Hence, it is suggested that the use of subcutaneous drains may decrease wound complications and soilage of dressings when operating on obese patients.

Subcutaneous Fat Closure Vs Subcutaneous Suction Drain The results of the study show no significant difference between two methods designed to minimise subcutaneous dead space in a strictly defined group of obese patients. Thus, of the two methods used in this study there is no decided advantage of one over the other in terms of morbidity.

\section{ACKNOWLEDGEMENT}

We would like to thank our patients for allowing us to carry out the study.

\section{REFERENCES}

1. De Holl D, Rodeheaver G, Edgerton MT, et al. Potentiation of infection by suture closure of dead space. Am J Surg 1974;127(6):716-20.

2. Cruise PJ, Foord R. The epidemiology of wound infection. A 10 -year prospective study of 62,939 wounds. Surg Clin North Am 1980;60(1):27-40.

3. Soper DE, Bump RC, Hurt WG. Wound infection after abdominal hysterectomy: effect of the depth of subcutaneous tissue. Am J Obstet Gynecol 1995;173(2):465-9. 


\section{Jemds.com}

4. Coveny EC, O'Dwyer PJ, Geraghty JG, et al. Effect of closing dead space on seroma formation after mastectomy--a prospective randomized clinical trial. Eur J Surg Oncol 1993;19(2):143-6.

5. O'Dwyer PJ, 0'Higgins NJ, James AG. Effect of closing dead space on incidence of seroma after mastectomy. Surg Gynecol Obstet 1991;172(1):55-6.

6. Condie JD, Fergusson DJ. Experimental wound infections: contamination versus surgical technique. Surgery 1961;50(2):367-71.

7. Naumann RW, Hauth JC, Owen J, et al. Subcutaneous tissue approximation in relation to wound disruption after cesarean delivery in obese women. Obstet Gynecol 1995;85(3):412-6.

8. Sherman Al. Letter to the editor. JAMA 1984:252-632.

\section{Original Research Article}

9. Buckwalter JA, Herbst CA. Perioperative complications of gastric restrictive operations. Am J Surg 1983;146(5): 613-8.

10. Del Valle GO, Combs P, Qualls C, et al. Does closure of Camper fascia reduce the incidence of post-cesarean superficial wound disruption? Obstet Gynecol 1992;80(6): 1013-6.

11. Hussain SA. Closure of subcutaneous fat: a prospective randomized trial. BJS 1990;77(1):107.

12. Maitland AIL, Mathieson AJM. Suction drainage. A study in wound healing. BJS 1970;57(3):193-7.

13. Gallup DC, Gallup DG, Nolan TE, et al. Use of a subcutaneous closed drainage system and antibiotics in obese gynecologic patients. Am J Obst Gyn 1996;175(2):358-62.

14. Kozol RA, Fromm D, Ackerman NB, et al. Wound closure in obese patients. Surg Gynecol Obstet 1986;162(5):442-4. 